\title{
Evidence that nitric oxide mechanisms regulate small intestinal motility in humans
}

\author{
A Russo, R Fraser, K Adachi, M Horowitz, G Boeckxstaens
}

\begin{abstract}
Background-Non-cholinergic nonadrenergic neural mechanisms involving nerves containing NO have been shown to modulate smooth muscle in the gastrointestinal tract, and it has been suggested that release from tonic NO inhibition may be important in the regulation of cyclical fasting small intestinal motility.

Aims - To evaluate the role of NO mechanisms in the regulation of fasting small intestinal motor activity in humans using a specific NO synthase inhibitor, $N^{\mathrm{G}}$ monomethyl-L-arginine ( L-NMMA).

Methods-In seven healthy male volunteers, duodenal and jejunal pressures were measured for four hours with a nine lumen manometric catheter. Volunteers attended on four separate days on which they received an intravenous infusion of either saline or L-NMMA $(0.5,2$, or 4 $\mathrm{mg} / \mathrm{kg} / \mathrm{h}$ ) in random order. Intravenous infusions began 10 minutes after completion of phase III of the migrating motor complex (MMC).
\end{abstract}

Results-The first episode of phase III activity occurred earlier after infusion of 2 and $4 \mathrm{mg} / \mathrm{kg} / \mathrm{h}$ L-NMMA than after infusion of $0.5 \mathrm{mg} / \mathrm{kg} / \mathrm{h}$ L-NMMA or saline (mean (95\% confidence interval) 52 (3668) and $57(18-97) v 116$ (69-193) and 145 (64-226) minutes respectively) with a resultant MMC cycle length of 82 (59-105) and $86(46-126) v 132(49-198)$ and 169 (98240) minutes respectively. The total number of phase III activities during the four hour recording was increased $(\mathrm{p}<0.05)$ by L-NMMA at a dose of 4 $\mathrm{mg} / \mathrm{kg} / \mathrm{h}(2$ (1-3)) but not at $2 \mathrm{mg} / \mathrm{kg} / \mathrm{h}(1.5$ (1-2)) or $0.5 \mathrm{mg} / \mathrm{kg} / \mathrm{h}(1.3(1-2))$ compared with saline (1.3 (0.6-2)). L-NMMA had no effect on the duration, velocity, number of contractions per minute, length of migration, or site of origin of phase III of the MMC. The duration of phase I activity was shorter $(p<0.05)$ with $4 \mathrm{mg} / \mathrm{kg} / \mathrm{h}$ L-NMMA than with saline (12 (1-23) $v 31(19-44)$ minutes).

Conclusions-These observations suggest that NO mechanisms play a role in the regulation of fasting small intestinal motor activity in humans. (Gut 1999;44:72-76)

Keywords: nitric oxide (NO); small intestine; motility; migrating motor complex (MMC)

During fasting, the upper gastrointestinal tract undergoes cyclical motor activity, the interdi- gestive migrating motor complex (MMC), which migrates down the small intestine. ${ }^{1}$ This motor activity is of variable duration and comprises three phases: a period of quiescence (phase I), a period of irregular motor activity (phase II), and a burst of activity at maximal slow wave frequency which migrates aborally (phase III). ${ }^{1}$ Phase III of the MMC lasts about 5-10 minutes and has been called the "housekeeper" of the gut, as the contractions propel cellular debris, secretions, undigested food, and bacteria distally along the small intestine. Absence of phase III activity is associated with bacterial overgrowth as a result of small intestinal stasis. ${ }^{2}$

Although it is recognised that both small intestinal slow waves and contractile activity are dependent on neural influences, the mechanisms mediating MMC activity are poorly defined. Recent studies in animals suggest that NO is an important inhibitory neurotransmitter throughout the gastrointestinal tract. $^{34}$ The role of NO mechanisms is optimally evaluated with the use of inhibitors of NO synthase rather than NO donors such as glyceryl trinitrate. In a variety of animal models, inhibition of NO synthase by $N^{\mathrm{G}}$-nitroL-arginine methyl ester (L-NAME) and $N^{\mathrm{G}}$ nitro-L-arginine (L-NNA) induces premature intestinal phase III activity and results in prolonged disruption of both fed and fasted small intestinal motility. ${ }^{5-8}$ There is also evidence that NO mechanisms are also important in gastrointestinal function in humans. Previous studies have employed either NO donors or in vivo scavengers of NO. The NO synthase inhibitor $\quad N^{\mathrm{G}}$-monomethyl-L-arginine (L-N MMA) has recently been used in humans as a supportive treatment for septic shock. ${ }^{9}$ We have now established that inhibition of NO synthase in humans using L-NMMA also results in phase III activity, suggesting that NO mechanisms may play a role in the control of the MMC.

\section{Methods}

SUBJECTS

Studies were performed in seven male volunteers, aged 21-39 years, body mass index 22.5-28.4. None had a history of gastrointestinal disease, previous abdominal surgery, or was taking medication. Smoking was prohibited from the evening before each study.

Abbreviations used in this paper: $M M C$, migrating motor complex; L-NMMA, $N^{6}$-monomethyl-L-arginine; L-NAME, $N^{G}$-nitro-L-arginine methyl ester; L-NNA, $N^{G}$-nitro-L-arginine; TMPP, transmucosal potential difference. 
Routine biochemical assessment of liver function showed it to be normal in all subjects before their enrolment in the study. The experimental protocol was approved by the human ethics committee of the Royal Adelaide Hospital and each subject gave written informed consent.

\section{MANOMETRIC TECHNIQUE}

Intraluminal pressures were recorded using a pneumohydraulic perfused manometric technique, with a flow rate of $0.5 \mathrm{ml} / \mathrm{min}$. The 200 $\mathrm{cm}$ manometric assembly (outer diameter 4.4 $\mathrm{mm}$ ) incorporated nine manometric lumina and a $2.5 \mathrm{~cm}$ diameter balloon located $5 \mathrm{~cm}$ from the weighted tip. The two most proximal side holes were separated by $5 \mathrm{~cm}$, and the remainder were positioned at $10 \mathrm{~cm}$ intervals. The position of the two most proximal side holes (antral and duodenal) relative to the pylorus was determined by measurement of transmucosal potential difference (TMPD). The assembly was inserted or withdrawn to keep the antral TMPD equal to or less than $-20 \mathrm{mV}$ and the duodenal TMPD equal to or more positive than $-15 \mathrm{mV}$, with a difference between the two of at least $15 \mathrm{mV}^{10}$ The TMPD channels measured both intraluminal pressure and TMPD and were perfused with degassed saline from separate reservoirs. All other channels were perfused with degassed distilled water from a common reservoir. Pressures were measured via transducers (Abbott Critical Care, Chicago, Illinois, USA) using purpose written manometric software (MAD; Dr C-H Malbert, Synectics, Stockholm, Sweden). Data were recorded on to a Macintosh Quadra 700 computer and a 12 channel chart recorder (Grass model 7E polygraph; Grass

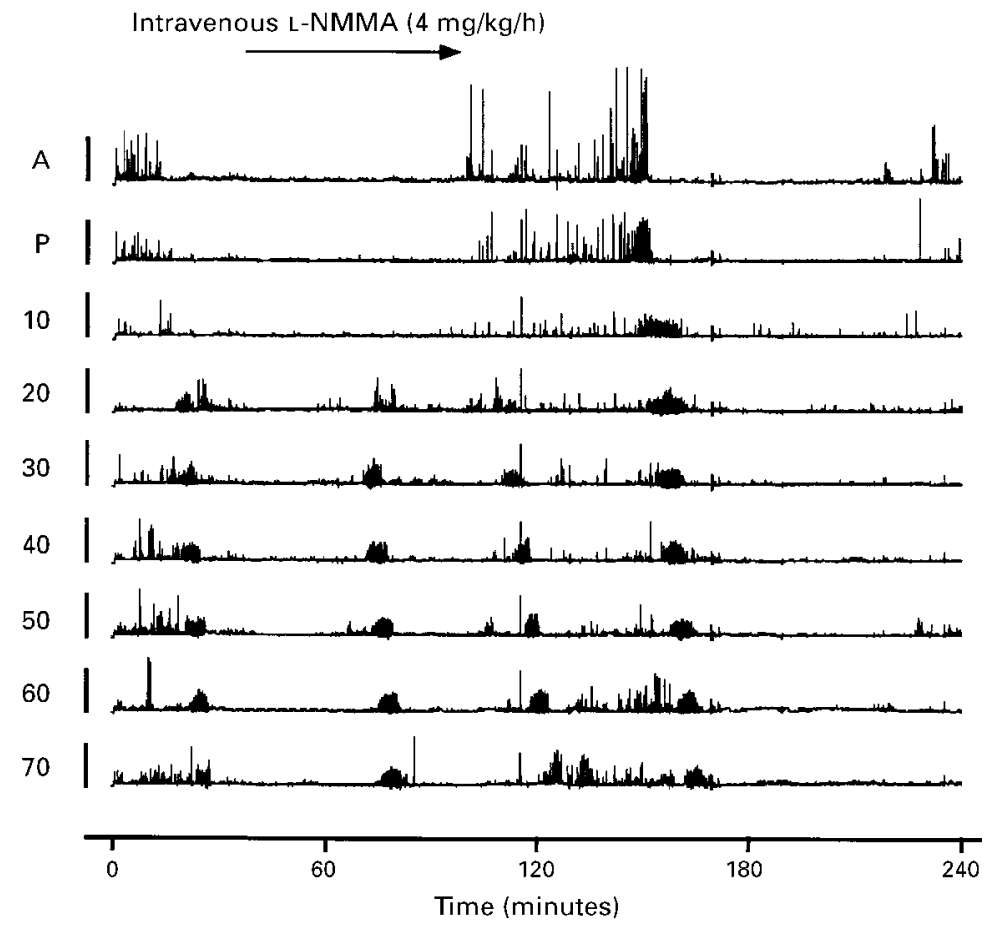

Figure 1 Manometric tracing showing example of early stimulation of phase III by 4 $m g / k g / h{ }_{L}-N M M A$. The position of the sensor is shown on the vertical axis $(A$, antrum; $P$ pylorus). Values are distance in $\mathrm{cm}$ from the pylorus in the duodenum and upper jejunum.
Instruments Co, Quincy, Massachusetts, USA) for subsequent analysis.

PROTOCOL

Subjects were studied for four hours on four occasions separated by at least seven days, during intravenous infusion of saline and
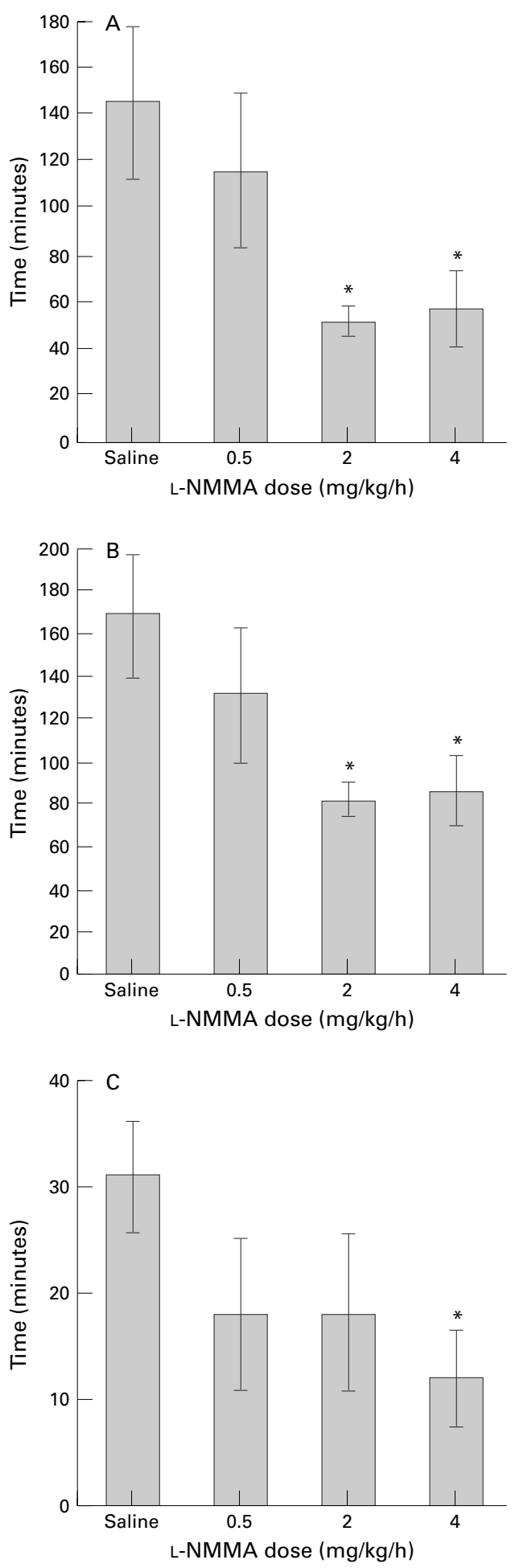

Figure 2 Effect of L-NMMA on (A) time to phase III activity after the baseline migrating motor complex, $(B)$ cycle length, and $(C)$ the duration of quiescence post-phase III activity (phase I). Results are given as means (SEM) ${ }^{*} p<0.05$ compared with the effect of saline (Mixed Mode ANOVA). 
Table 1 Pressure waves per minute, velocity, duration and length of migration of phase III of the migrating motor complex during infusion of saline and three doses of $L-N M M A$

\begin{tabular}{lllll}
\hline & \multicolumn{4}{l}{$L-N M M A(\mathrm{mg} / \mathrm{kg} / \mathrm{h})$} \\
\cline { 2 - 5 } & Saline & 0.5 & 2 & 4 \\
\hline Pressure waves per min & $11.4(11.1-12.7)$ & $11.4(10.8-11.8)$ & $11.1(10.7-11.5)$ & $11.3(10.7-11.8)$ \\
Velocity (cm/min) & $7.7(5-10.4)$ & $10.3(5-12.9)$ & $6.7(4.7-8.7)$ & $5.5(1.8-9.1)$ \\
Duration (min) & $6.0(4.0-8.0)$ & $7.4(3.2-10.8)$ & $5.7(4.3-7.1)$ & $4.7(2.8-6.6)$ \\
Length of migration (cm) & $64.3(62.8-65.8)$ & $72.5(69.7-75.3)$ & $57(26.5-87.5)$ & $75 \quad(75-75)$ \\
\hline
\end{tabular}

Data are means and $95 \%$ confidence intervals.

L-NMMA (Calbiochem, Sydney, NSW, Australia) at doses of $0.5,2$ or $4 \mathrm{mg} / \mathrm{kg} / \mathrm{h}$ in single blind randomised fashion (only five subjects received $0.5 \mathrm{mg} / \mathrm{kg} / \mathrm{h}$ ). At about 0900, after an overnight fast, the manometric assembly was introduced via an anaesthetised nostril. Volunteers lay on their right side until the tip of the catheter passed the pylorus. The balloon was then inflated with $7 \mathrm{ml}$ air to facilitate passage of the catheter along the intestine. When the two most proximal side holes were positioned in the antrum and proximal duodenum, the balloon was deflated.

An intravenous cannula was placed in the antecubital vein of the right arm for infusion of either saline or L-NMMA which was commenced 10 minutes after an episode of phase III activity had been completed. Saline was infused at exactly the same rate as the L-NMMA infusion ( $43 \mathrm{ml} / \mathrm{min})$. Manometric measurements were performed for four hours. To minimise the possibility of an adverse reaction to L-NMMA at the higher dose, intravenous infusions of L-NMMA commenced at $0.5 \mathrm{mg} / \mathrm{kg} / \mathrm{h}$ for five minutes followed by 1 $\mathrm{mg} / \mathrm{kg} / \mathrm{h}$ for five minutes followed by either 2 or $4 \mathrm{mg} / \mathrm{kg} / \mathrm{h}$. For the studies using 0.5 and 2 $\mathrm{mg} / \mathrm{kg} / \mathrm{h}$ L-NMMA, a two hour infusion was followed by a two hour post-infusion period. Because of the substantial cost of L-NMMA, it was only practical to use $4 \mathrm{mg} / \mathrm{kg} / \mathrm{h}$ as a one hour infusion followed by three hours of postinfusion recording. Blood pressure and heart rate were monitored every five minutes for the first 30 minutes and thereafter every 10 minutes for the duration of each study. Subjects were given a light meal before leaving the laboratory. Screens for haemoglobin and liver enzyme abnormalities ( $\gamma$-glutamyl transpeptidase, aspartate aminotransferase, alkaline phosphatase) were repeated four days after each infusion.

ANALYSIS OF SMALL INTESTINAL MOTILITY

The occurrence and timing of small intestinal phase III activity were analysed manually. Phase III was defined as a burst of pressure waves with a frequency greater than 10 per minute and a duration longer than two minutes, which migrated more than $30 \mathrm{~cm}-$ that is, four side holes. ${ }^{10}$ The frequency, duration, velocity, length of pressure wave migration, and origin (antral, duodenal, or jejunal) of phase III during the four hour recording period were calculated. The time between the commencement of intravenous infusion and the next episode of phase III, and the duration of quiescence after this episode of phase III (phase I) were also determined.

STATISTICAL ANALYSIS

Data are presented as means and 95\% confidence intervals except where otherwise specified. Differences in motor activity, blood pressure, and heart rate between the four experiments were evaluated using Mixed Mode ANOVA (SAS version 6.11). Differences in the site of origin of phase III were assessed using a $\chi^{2}$ test. $p<0.05$ was considered to be significant in all analyses.

\section{Results}

The treatments were well tolerated by all volunteers. L-NMMA had no significant effect on either blood pressure or heart rate when compared with intravenous saline infusion (data not shown). No subject reported dysphagia or chest pain following infusion of L-NMMA, and there were no changes in either haemoglobin or liver function (data not shown).

The lowest dose of L-NMMA $(0.5 \mathrm{mg} / \mathrm{kg} / \mathrm{h})$ had no effect on small intestinal motility, whereas the two higher doses induced premature phase III activity (figs 1 and 2). The time to onset of the first episode of phase III activity after the start of intravenous infusion was less $(\mathrm{p}<0.05)$ after both $2 \mathrm{mg} / \mathrm{kg} / \mathrm{h}$ (52 (36-68) minutes) and $4 \mathrm{mg} / \mathrm{kg} / \mathrm{h}$ (57 (18-97) minutes) but not $0.5 \mathrm{mg} / \mathrm{kg} / \mathrm{h}$ (116 (69-193) minutes) L-NMMA when compared with saline (145 (64-226) minutes). In addition, L-NMMA reduced the MMC cycle length: 82 (59-105) minutes $(2 \mathrm{mg} / \mathrm{kg} / \mathrm{h})$ and $86(46-126)$ minutes ( $4 \mathrm{mg} / \mathrm{kg} / \mathrm{h})$ compared with 132 (49-198) (0.5 $\mathrm{mg} / \mathrm{kg} / \mathrm{h}$ ) and $169(98-240)$ minutes (saline) $(\mathrm{p}<0.05$ for each (fig 2)).

In all studies phase III activity originated in the antrum or duodenum and L-NMMA had no effect on the site of origin of phase III activity. The number of phase III activities was greater $(\mathrm{p}<0.05)$ during infusion of $4 \mathrm{mg} / \mathrm{kg} / \mathrm{h}$ L-NMMA (2 (1-3)) but not $2 \mathrm{mg} / \mathrm{kg} / \mathrm{h}(1.5$ (1-2)) or $0.5 \mathrm{mg} / \mathrm{kg} / \mathrm{h}(1.3(1-2))$ compared with saline (1.3 (0.6-2)). L-NMMA had no effect on the duration, velocity, or length of migration of phase III activity or the number of pressure waves per minute during phase III activity (table 1). After the first phase III activity after the intravenous infusion, the duration of phase I activity was reduced $(\mathrm{p}<0.05)$ during infusion of L-NMMA at $4 \mathrm{mg} / \mathrm{kg} / \mathrm{h}$ (12 (1-23) minutes) but not at $2 \mathrm{mg} / \mathrm{kg} / \mathrm{h}(18(2-39) \mathrm{min}-$ utes) or $0.5 \mathrm{mg} / \mathrm{kg} / \mathrm{h} \mathrm{(18} \mathrm{(3-31)} \mathrm{minutes)}$ 
compared with saline (31 (19-44) minutes) (fig 2). The proportion of the MMC cycle occupied by phase I was, however, unchanged.

\section{Discussion}

The major observation in this study is that inhibition of endogenous NO synthase by L-NMMA results in early phase III activity in the human small intestine. These data extend work previously performed in animals to humans and provide further evidence for the concept that NO plays a role in the regulation of small intestinal motility in humans. The results are also consistent with the hypothesis that small intestinal motility is under tonic inhibition by nitrergic mechanisms, and release from this inhibition results in phase III activity. ${ }^{11}$

The role of NO mechanisms is characteristically evaluated by reducing NO production by the use of inhibitors to block biosynthesis or removing $\mathrm{NO}$ with a scavenging molecule such as haemoglobin. ${ }^{12} \mathrm{~A}$ more direct approach to investigating the role of endogenous $\mathrm{NO}$ in humans is by reducing NO synthesis using specific inhibitors. It has not previously been possible to conduct such experiments in humans because of concerns about the safety of NO synthase inhibitors such as L-NAME and L-NNA. The novel NO synthase inhibitor L-NMMA has, however, recently been used in both cardiovascular research and in patients with septic shock with few adverse events. ${ }^{913}$ Although $\mathrm{NO}$ is important in blood pressure regulation, we did not observe any effect on blood pressure or heart rate in this study, in contrast with other studies that have investigated the effect of L-NMMA. However, in these studies in healthy volunteers, higher doses of L-NMMA were used which were infused over a shorter period of time-for example, 3.6-6.7 mg/kg over 15 minutes-and only minor increases in blood pressure were reported. ${ }^{13}$ In contrast with a study of the role of NO mechanisms in oesophageal motility, in which NO was removed by recombinant human haemoglobin, we did not observe side effects such as chest pain or dysphagia. ${ }^{12}$ Our study therefore suggests that L-NMMA is a useful and safe agent for the investigation of the role of NO mechanisms in the gastrointestinal tract in both health and disease. Furthermore, as abnormalities of phase III activity are frequently associated with clinical problems such as bacterial overgrowth or diarrhoea, manipulation of small intestinal motility by NO synthase inhibitors may also have potential therapeutic applications.

This study shows a dose-related alteration in small intestinal motility by L-NMMA: there was no change in motor patterns at the lowest $(0.5 \mathrm{mg} / \mathrm{kg} / \mathrm{h})$ dose, stimulation of phase III activity at an intermediate $(2 \mathrm{mg} / \mathrm{kg} / \mathrm{h})$ and highest $(4 \mathrm{mg} / \mathrm{kg} / \mathrm{h})$ doses, and a decrease in the duration of motor quiescence at the highest dose. Differential effects with NO synthase inhibitors have not been previously described. In animals, more potent inhibitors such as L-NAME and L-NNA (the latter is about 10 times more potent than L-NMMA ${ }^{14}$ ) have been administered at doses likely to block NO synthesis completely. ${ }^{78}$ In these studies, short term inhibition of NO synthesis by L-NNA and L-NAME was associated with prolonged disruption of both fed and fasting small intestinal motor activity. ${ }^{78}$ Thus in the dog, L-NNA infused at $3.75 \mathrm{mg} / \mathrm{kg} / \mathrm{h}$ for four hours induced premature phase III activity followed by prolonged disruption of the MMC cycle, probably reflecting motor disinhibition as a result of complete blockade of NO synthesis. Complete disruption of MMC activity by L-NNA or L-NAME infusion, was followed by a period when MMC cycle length was shortened significantly, probably as a result of partial inhibition during gradual recovery from the NO synthase antagonist. In this study, L-NMMA at a dose of $4 \mathrm{mg} / \mathrm{kg} / \mathrm{h}$ produced an effect that resembled that of L-NNA and L-NAME in the dog during the recovery period. The relatively low dose of L-NMMA and the lack of effect on blood pressure or heart rate in our study are consistent with the concept of an incomplete blockage of $\mathrm{NO}$ responses.

The mechanisms underlying the initiation or triggering of phase III and the interdigestive motility pattern are unknown. The intestine contracts at maximal frequency during phase III, possibly reflecting a loss of inhibitory influences which could result from decreased endogenous synthesis of NO. Further support for this hypothesis is provided indirectly by reports of stimulation of phase III by opioids and somatostatin, which also inhibit $\mathrm{NO}$ release. ${ }^{1516} \mathrm{NO}$ synthase is found throughout the gastrointestinal tract and also within the central nervous system and the site of action of intravenous L-NMMA in the current study is therefore unclear. However, central inhibition of NO synthase is associated with inhibition of gastric and duodenal phase III activity, ${ }^{17}$ and it therefore appears likely that the effects of intravenous administration of L-NMMA result from a peripheral action, most probably within the enteric nervous system.

In conclusion, transient inhibition of $\mathrm{NO}$ synthesis by L-NMMA is associated with stimulation of phase III activity and a reduction in quiescence after this premature activity. Our study also indicates that L-NMMA is a useful and safe agent for the investigation of the role of NO mechanisms in the human gastrointestinal tract; manipulation of NO synthase activity may potentially be of therapeutic value.

1 Szurszewski J. A migrating electric complex of the canine small intestine. Am f Physiol 1969;217:1757-63.

2 Vantrappen G, Janssens J, Hellemans J, et al. The interdigestive motor complex of normal subjects and patients with bacterial overgrowth of the small intestine. $\mathcal{F}$ Clin Invest 1977;59:1158-66.

3 Bult H, Boeckxstaens G, Pelckmans P, et al. Nitric oxide as an inhibitory non-adrenergic non-cholinergic neurotransmitter. Nature 1990;345:346-7.

4 Stark M, Szurszewski J. Role of nitric oxide in gastrointestinal and hepatic function and disease. Gastroenterology 1992;103:1928-49.

5 Hellstrom P, Ljung T. Nitrergic inhibition of migrating myoelectric complex in the rat is mediated by vasoactive intestinal peptide. Neurogastroenterol Motil 1996;8:299306.

6 Maczka M, Thor P, Lorens K, et al. Nitric oxide inhibits the myoelectric activity of the small intestine in dogs. F Physiol Pharmacol 1993;44:31-42. 
7 Sarna S, Otterson M, Ryan R, et al. Nitric oxide regulates migrating motor complex cycling and its postprandial disruption. Am f Physiol 1993;265:G759-66.

8 Rodriguez-Membrilla A, Martinez V, Jimenez M, et al. Is nitric oxide the final mediator regulating the migrating myoelectric complex cycle? Am f Physiol 1995;268:G20714.

9 Petros A, Lamb G, Leone A, et al. Effects of a nitric oxide synthase inhibitor in humans with septic shock. Cardiovasc Res 1994;28:34-9.

10 Russo A, Fraser R, Horowitz M. The effect of acute hyperglycaemia on small intestinal motility in normal subjects. Diabetologia 1996:39:984-9.

11 Gustafsson B, Delbro D. Tonic inhibition of small intestinal motility by nitric oxide. F Auton Nerv Syst 1993;44:179-87.

12 Murray J, Ledlow A, Launspach J, et al. The effects of recombinant human hemoglobin on esophageal motor function in humans. Gastroenterology 1995;109:1241-8.
13 Hansen J, Jacobsen T, Victor R. Is nitric oxide involved in the tonic inhibition of central sympathetic outflow in humans? Hypertension 1994;24:439-44.

14 Boeckxstaens GE, Pleckmans PA, Bult H, et al. Nonadrenergic, non-cholinergic relaxation mediated by nitric oxide in the canine ileocolonic junction. Eur 7 Pharmacol 1990;190:239-46.

15 Fox-Threlkeld JE, Daniel EE, Christinck F, et al. Identification of mechanisms and sites of actions of mu and delta opioid receptor activation in the canine intestine. $f$ opioid receptor activation in the can

16 Vergara P, Woskowska Z, Cipris S, et al. Somatostatin excites canine ileum ex vivo: role for nitric oxide? Am $\mathcal{F}$ Physiol 1995;269:G12-21.

17 Ohta D, Lee CW, Sarna SK, et al. Central inhibition of nitric oxide synthase modulates upper gastrointestinal motor activity. Am f Physiol 1997;272:G417-24. 